\title{
GÊNERO, MÍDIA E EDUCAÇÃO: DIÁLOGOS NA INFÂNCIA E NA PRÉ-ADOLESCÊNCIA
}

\author{
Tuany de Menezes Oliveira ${ }^{\mathrm{i}}$ \\ Paula Teixeira Araujoii \\ Luís Paulo de Carvalho Piassiii
}

\section{Resumo}

Neste artigo, refletimos sobre a utilização de produtos midiáticos como porta de entrada para o diálogo sobre relações de gênero com crianças e pré-adolescentes, a partir dos resultados de atividades realizadas em escolas públicas de São Paulo. As intervenções foram formuladas e realizadas pelo grupo E.M.M.A. (Estudos sobre a Mulher e as Minorias na Arte-Ciência), do projeto Banca da Ciência. Após reflexões teóricas e intervenções, pudemos concluir que, é possível utilizar produtos midiáticos como porta de entrada para o diálogo sobre relações de gênero e que, a partir das representações das identidades femininas que estão presentes nessas mídias, é possível discutir diversos temas relacionados à questão do sexo, do gênero, da orientação sexual e das identidades de forma didática e lúdica.

Palavras-chave: Gênero. Mídia. Educação. Infância. Pré-Adolescência.

\section{GENDER, MEDIA AND EDUCATION: DIALOGUES IN THE CHILDHOOD AND PRE-ADOLESCENCE}

\begin{abstract}
In this article, we were reflected on the use of media products as a gateway to the dialogue about gender relations with children and pre-adolescents, based on the results of activities carried out in public schools in São Paulo. The interventions were formulated and carried out by the group E.M.M.A. (Studies about Women and Minorities in Art-Science) of the "Banca da Ciência" project. After theoretical reflections and interventions, we could conclude that it is possible to use media products as a gateway to the dialogue about gender relations and that, based on the representations of the feminine identities that are in these media, it is possible to discuss various issues related to sex, gender, sexual orientation and identities in a didactic and playful way.
\end{abstract}

Keywords: Gender. Media. Education. Childhood. Pre-Adolescence. 


\section{Introdução}

O conceito de gênero parece ter surgido inicialmente entre feministas americanas, "que queriam enfatizar o caráter fundamentalmente social das distinções baseadas no sexo" (SCOTT, 1995, p. 72). A partir disso, esse conceito se apresentou cada vez mais como fruto de discussões políticas, ideológicas e teóricas. A discussão inicial era que sexo e gênero eram distintos, enquanto o sexo seria biológico, o gênero seria construído socialmente, ou seja, mulheres estariam sendo socializadas para serem mulheres, enquanto homens estariam sendo socializados para serem homens. Contudo, posteriormente, também essa dicotomia começou a ser questionada e vimos surgir novas teorias, como a queer, que contestam também o caráter biológico do sexo. Todas essas teorias acerca do conceito de gênero são importantes e válidas, dependendo do tipo de estudo que se pretende fazer.

Relações de gênero permeiam a mídia. Em produtos midiáticos há, frequentemente, uma sub-representação das mulheres e produtos midiáticos direcionados ao público feminino são, normalmente, classificados como inferiores pela crítica. Além disso, em uma infinidade de produtos midiáticos, mulheres e meninas são representadas de forma insatisfatória ou até misógina. Constantemente, corpos femininos são altamente expostos e objetificados e exibem padrões de beleza que são inalcançáveis para as mulheres. As personagens femininas são, continuamente, representadas como sendo mães, esposas, donas de casa, prêmios, rivais, consumistas, entre outros estereótipos, que acabam por naturalizar certos comportamentos como relacionados às mulheres, quando não o são. Ainda que, novas representações, em parte um pouco mais positivas, estejam surgindo.

Segundo Gauntlett (2008), a mídia e as comunicações são elementos centrais da vida moderna, enquanto as questões de gênero e sexualidade permanecem no núcleo de como nós pensamos nossa identidade. Com tantas representações da mulher e do homem na mídia é altamente improvável que essas ideias não tenham impacto no nosso próprio senso de identidade. Na sociedade moderna as pessoas passam grande parte do tempo assistindo a TV, lendo revistas, vendo propagandas ou indo ao cinema e são incapazes de negar a cultura pop e a publicidade. Desta forma, muitas informações veiculadas pela mídia entram na cabeça dos indivíduos mesmo que eles não as vejam como informação ou não estejam prestando atenção. Logo, é inevitável que não sejamos afetados por essas experiências e pelo ponto de vista de outras pessoas, ainda que não sejamos passivos diante delas.

Mesmo possuindo uma dimensão central tanto na vida dos indivíduos como na organização social, as relações de gênero não são suficientemente discutidas pelas principais 


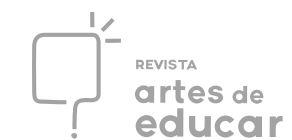

instituições formadoras: a família, a escola e a mídia, ainda que isto esteja aos poucos mudando. Há algum tempo tem se discutido sobre a importância de trazer o debate sobre gênero para a sala de aula, mas, obviamente, há ainda resistência em relação a isto. Neste trabalho, defendemos que é fundamental que o debate sobre gênero seja levado não só para a sala de aula, mas também para a escola de forma geral, para a família, para a mídia, para a política, enfim, que as reflexões sobre as relações de gênero invadam todos os espaços. E é essa invasão que almejamos no grupo de trabalho E.M.M.A.

O grupo E.M.M.A. (Estudos sobre a Mulher e as Minorias na Arte-Ciência) faz parte do projeto Banca da Ciência, que possui duas modalidades: o A.L.I.C.E. (Arte e Lúdico na Investigação em Ciências nos Espaços Educativos) e o J.O.A.N.I.N.H.A. (Jogar, Observar, Aprender, Narrar - Investigações sobre a Natureza, Humanidades e Artes). Ambas têm como objetivo realizar atividades lúdicas e didáticas em espaços formais e não formais de educação que devem prever três vértices: (1) educador, (2) materiais e (3) educandos e que coloquem os educandos como protagonistas, que desenvolvem seus próprios projetos em uma perspectiva crítica e investigativa. A modalidade J.O.A.N.I.N.H.A. tem como público-alvo crianças, entre quatro e oito anos, enquanto a modalidade A.L.I.C.E. tem como principal público-alvo préadolescentes entre doze e catorze anos.

Além das crianças e pré-adolescentes, o projeto envolve outros atores. Inicialmente, os seus idealizadores, professores da USP e da UNIFESP. Em seguida, alunos de mestrado e de doutorado, orientandos desses professores, e coordenadores dos grupos de trabalho. Então, os alunos de graduação da USP e da UNIFESP, bolsistas e voluntários, que cursam diferentes graduações, como: Lazer e Turismo, Marketing, Gestão em Políticas Públicas, Têxtil e Moda, Licenciatura em Ciências da Natureza, entre outras, e que participam das formulações e das intervenções e desenvolvem pesquisas (a maioria deles recebe bolsas de pesquisa, como PUB Programa Unificado de Bolsas e PIBID - Programa Institucional de Bolsa de Iniciação à Docência). E, finalmente, os professores das escolas participantes.

Os atores atuam em seis grupos de trabalho. O grupo R.I.T.A., que recebe este nome em homenagem à cantora brasileira Rita Lee, tem como foco a utilização de expressões musicais e rítmicas; o L.U.C.I.A., nomeado em homenagem à escritora Lucia Machado de Almeida, preocupa-se com práticas de leitura; o L.Y.R.A., referência à Jacqueline Lyra, engenheira aeroespacial brasileira da NASA, problematiza os impactos sociais da tecnologia espacial e robótica; o E.M.M.A., uma homenagem à atriz britânica e ativista feminista Emma Watson, abarca questões de gênero e de minorias; o D.I.A.N., assim chamado em homenagem à Dian Fossey, zoóloga e primatologista norte-americana, debate questões sobre os direitos animais e 
ambientais; e o M.A.R.I.A., homenagem à atriz mexicana María Antonieta de las Nieves, investiga as manifestações da alegria e do riso.

Cada grupo realiza reuniões semanais para discutir e desenvolver propostas didáticas de acordo com as suas temáticas, definidas pelos nomes apresentados acima, as quais são aplicadas em cada uma das escolas participantes do projeto, sob o auxílio do professor de cada turma. Consideramos nosso trabalho como educação não formal, pois não envolve currículo, disciplinas, matérias ou salas de aula. Não são aulas, são intervenções educativas e lúdicas na sociedade. Não obstante, frequentemente, nós realizamos as intervenções em espaços formais de educação. Atualmente, atuamos em duas escolas municipais de ensino fundamental, uma de educação infantil e um centro para crianças e adolescentes, todos localizados na zona leste do município de São Paulo. Porém, uma das aplicações descritas ocorreu em uma escola de Guarulhos/SP, pois iniciamos este projeto a partir de uma parceria com esta prefeitura, e por motivos de dificuldade de deslocamento dos monitores que realizam as intervenções, optamos por não continuarmos nesta região. Com as crianças, as atividades são realizadas durante o tempo da aula, enquanto com os pré-adolescentes, as atividades são realizadas no horário de contraturno e eles aderem espontaneamente a elas. As atividades contam também com o envolvimento dos professores das escolas.

Neste artigo, pretendemos focar nas atividades desenvolvidas pelo grupo E.M.M.A..O nome do grupo foi escolhido como homenagem à atriz Emma Watson, não só pelo fato dela ser uma celebridade ícone entre os e as pré-adolescentes e ser a intérprete de uma famosa personagem que possui diversos pontos positivos no que diz respeito às representações midiáticas do feminino, mas, principalmente, pelo fato de Emma ter sido nomeada, em 2014, Embaixadora da Boa Vontade da Agência ONU Mulheres, e promover um movimento de solidariedade chamado HeForShe (ElesPorElas), que luta pela igualdade de gênero e pelo empoderamento das mulheres através do envolvimento de homens e meninos na remoção de barreiras sociais e culturais que impedem mulheres de atingir seu potencial ${ }^{\mathrm{iv}}$.

As atividades desenvolvidas pelo E.M.M.A. pretendem contribuir para estruturar e fortalecer a capacidade dos e das participantes em gerar reflexões sobre questões de gênero, associadas às mídias, às artes e às ciências, utilizando para isso produtos midiáticos, como séries, filmes, videoclipes e quadrinhos. Neste artigo, nós objetivamos apresentar e analisar alguns resultados obtidos em intervenções com crianças e pré-adolescentes, realizadas em 2015. Os dados foram coletados através de filmagens, sequências fotográficas orientadas (por eventos verificáveis), anotações e produtos (o que foi produzido pelos próprios participantes). Após as oficinas, foi feita uma reconstrução narrativa. As atividades foram analisadas através de teorias 
dos Estudos Culturais e Estudos de Gênero. No primeiro capítulo, focamos nas questões relacionadas à infância e no segundo à pré-adolescência.

Após reflexões teóricas e diversas intervenções, pudemos concluir que, é sim possível utilizar produtos midiáticos como porta de entrada para o diálogo sobre relações de gênero com crianças e pré-adolescentes, e que, a partir das representações das identidades femininas que estão presentes nessas mídias, é possível discutir diversos temas relacionados à questão do sexo, do gênero, da orientação sexual e das identidades de forma didática, lúdica e eficaz. Sabemos que, muitos produtos culturais são machistas, então, acreditamos que cabe a nós nos questionarmos o que podemos fazer para mudar isso, o que podemos fazer para que crianças e pré-adolescente apropriem-se disso de forma crítica. Logo, intentamos que esse artigo possa contribuir para essa reflexão e inspirar outros trabalhos neste campo.

\section{Gênero, Mídia, Educação e Infância}

A concepção de infância é uma descoberta relativamente recente se considerarmos que reflexões mais específicas voltadas à criança surgem em meio a grandes transformações do século XVIII (FARIA e FINCO, 2011; GUIZZO, BECK e FELIPE, 2013), através das quais esta passa a ser reconhecida. A centralização da figura infantil resultou em um favorecimento da compreensão em destinar cuidados específicos a este público, permitindo que aos poucos passasse a ser "cuidadosamente segregada, tornando-se um objeto específico de atenção no plano social: daí em diante suas tarefas e brincadeiras teriam o único objetivo de contribuir para a própria formação" (SHÉRER, 2009, p. 17).

Atualmente, a ideia natural de infância, representada por uma imagem universal, começa a ser questionada, a partir de perspectivas pós-estruturalistas, passando a considerar aspectos sociais, culturais e históricos que atravessam suas realidades. Pesquisas recentes destacam a necessidade de articular ao fator idade outros marcadores diferenciais, como: gênero, classe, etnia/raça, sexualidade, capazes de evidenciar a multiplicidade de se vivenciar as infâncias (GUIZZO, 2011; FINCO 2010).

Os pesquisadores Steinberg e Kincheloe (2001) contribuem para esta reflexão a partir de seu estudo "Cultura Infantil: a construção corporativa da infância", ao afirmarem perceber a infância muito além de uma entidade biológica, dada as condições sociais e históricas que criam novas subjetividades nas crianças. Segundo eles, a cultura infantil passou por inúmeras mudanças causadas por alterações no campo socioeconômico, a partir do contexto histórico pósindustrial, as quais resultaram numa condição bastante particular de educação, a partir de 1950. 
Grande parte das experiências das crianças passou a ser massivamente produzida por corporações de domínio privado - visando o lucro. Na família, na escola, na religião e demais instituições frequentadas pelas crianças, a concepção de educar se faz presente, contudo não necessariamente respeitando suas particularidades ou interpretações de mundo.

Nesta perspectiva, sabemos que boa parte do processo de compreensão do mundo pela criança ocorre através da imagem. Como afirma Coelho, a imagem auxilia a criança a interagir com o mundo visto que, esta ainda é carente de experiências e vivências para entender tanto a palavra escrita quanto o seu significado simbólico e abstrato, desse modo "a imagem fala tanto quanto a palavra" (COELHO, 2000, p. 196). A partir da interpretação das imagens, respeitando os seus diferentes estágios de desenvolvimento, a criança conseguirá nomear os familiares, os animais, objetos que a cercam, desenvolvendo uma série de habilidades necessárias à sua formação. A presença das imagens estimula a percepção visual e a comunicação, concretiza as relações abstratas e fixa de maneira mais significativa às impressões do real, além de enriquecer a imaginação com o universo de informações que o material apresenta (COELHO, 2000).

Por sua vez, as imagens funcionam como símbolos que representam um conjunto de significados, pertencentes a um determinado contexto cultural. O termo representação é essencial para a compreensão do processo de construção das identidades, devido ao fato de elementos ideológicos estarem intrinsecamente ligados tanto ao "processo de representação, figuração, imagem e retórica, quanto um processo de discurso e ideias" (KELLNER, 2001, p. 82). Assim, como observado em algumas pesquisas (STEINBERG e KINCHELOE, 2001; FINCO, 2010; GUIZZO, 2011; VIZACHRI, 2014), os produtos pertencentes a denominada cultura infantil, muito além de entreter, veiculam visões sobre o mundo para as crianças. Esse caráter pedagogizante dos artefatos culturais produz, através de diversos elementos textuais, discursos que operam de forma a ensinar maneiras de ser e estar na sociedade.

O modo como determinadas ideias são transmitidas veiculam uma forma essencializada dos comportamentos, descaracterizando um processo construído socialmente, ocasionando um efeito de naturalização e normalização daqueles. Em muitos casos, não é difícil perceber certas construções textuais que incitam a (re)produção e manutenção de estereótipos, como os de gênero e sexualidade, por exemplo, em brinquedos, filmes, histórias orais, livros, revistas, músicas, entre outros produtos que constituem a cultura infantil. Esta, por sua vez, pode ser interpretada como inofensiva e ser utilizada em diferentes espaços sem um olhar mais crítico, incluindo o da escola.

Baseados no referencial pedagógico de Paulo Freire, adotamos uma visão de que a escola é um espaço de transformação social. Portanto, é preciso estar atento aos efeitos que 
determinadas práticas culturais exercem, conforme Argüello apresenta em sua dissertação de mestrado, intitulada 'Dialogando com as crianças sobre gênero através da literatura infantil',

práticas culturais se encarregam de exercer uma ação formadora para conduzir os sujeitos por caminhos seguros e "certos" na conformação de suas identidades de gênero e para isso, uma série de artefatos é acionada no sentido de produzir significados e sentidos que garantam a normalização desejada (ARGÜELLO, 2005, p. 42).

É notável que, além de formar intelectualmente, os ambientes escolares ultrapassam o ensino de conceitos relacionados a determinadas áreas do conhecimento, contribuindo assim para o processo de construção do sujeito e de uma visão do mundo em que está inserido, sendo uma delas, as marcas das relações de gênero. Especificamente quanto à fase infantil, o comportamento "passa a ser adestrado logo nas primeiras idades, mas se intensifica quando chega a faixa etária dos 7 aos 14 anos, sobretudo em relação ao corpo e conduta das meninas" (RIBEIRO, 2006, p. 11).

Sendo assim, examinar os diferentes artefatos pertencentes à pedagogia cultural e escolar é necessário e fundamental papel do educador, na tentativa de encontrar e expor forças aparentemente invisíveis, que atuam na influência de hábitos e percepções das crianças (STEINBERG e KINCHELOE, 2001). Tal ação não deve se relacionar à percepção de nuances e aspectos ideológicos "negativos" no processo de construção do sujeito, e por consequência retirar ou negar a presença destes perante os alunos. Pelo contrário, o papel do educador é justamente o de reconhecer a importância e o interesse positivo que as crianças apresentam por estes aspectos, propiciando momentos de conversa e reflexão sobre as temáticas nele apresentadas, além de oferecer outras atividades e materiais para ampliar a quantidade de referenciais aos quais a criança tem acesso. Estas ações podem favorecer o desenvolvimento de um olhar crítico e mais amplo sobre temas sociais.

A possibilidade de elementos do contexto social e cultural implicarem em marcas expressas nos sujeitos que neles convivem, demonstra ser de extrema relevância analisar os processos, estratégias e saberes pelos quais essas práticas educativas socioculturais ocorrem, sobretudo se quisermos investir em intervenções que permitam modificar em alguma medida as relações vigentes desiguais entre mulheres e homens da nossa sociedade. Deste modo, descrevemos brevemente uma sequência didática realizada com uma turma de segundo ano do ensino fundamental I, alunos entre sete e oito anos, da região de Guarulhos/SP. Cabe ressaltar que os livros utilizados nesta proposta foram previamente analisados com apoio da semiótica e análise do discurso, porém, neste artigo focamos apenas na parte prática. 
A proposta didática com o tema "joaninha" foi planejada para que as crianças recontassem uma narrativa, utilizando-se de outros recursos, como desenhos das personagens e materiais adaptados para confecção do cenário. Tal proposta foi dividida em duas etapas realizadas em dias distintos, contendo três situações didáticas distintas cada, das quais focamos especificamente nas reflexões referentes às relações de gênero.

A primeira parte contou com a peça de teatro de fantoches, roda de conversa e um jogo adaptado, chamado "pega-pega da cadeia alimentar", simulando a brincadeira do pega-pega entre presa e predador com os personagens da história. Após a apresentação da peça de teatro de fantoches, baseada no livro "A joaninha muito preguiçosa" (TICKLE e FINN, 2010), foram realizadas perguntas em uma roda de conversa, para abordar diferentes aspectos da vida do inseto e da narrativa apresentada: O que aconteceu na história? / Qual é a cor da joaninha? / Porque ela é chamada de preguiçosa? / O que ela faz ao longo da história? / A joaninha é macho ou fêmea? / Alguém já viu a joaninha? / De acordo com a história, onde ela vive e o que come? / Vocês gostam da joaninha? Por quê? / Quem cuida da joaninha na história?, entre outras. Para a realização do jogo, cada criança teve um papel pré-definido: joaninha, pulgão e pássaro, sendo identificada com um crachá com a respectiva imagem do animal que representava. Deste modo, o jogo consistiu em cada predador "capturar" a sua respectiva presa, assim, o pássaro deveria alcançar a joaninha, esta pegar o pulgão, e este último pegar uma folha. O objetivo desta atividade foi evidenciar os diferentes papéis ocupados por cada espécie na cadeia alimentar, não denotando, necessariamente, um caráter de valor positivo ou negativo para quem é presa ou predador, ressaltando para o fato de permitir com que as crianças compreendessem que não há distinção de comportamento do macho e da fêmea das diferentes espécies .

No segundo dia, foi apresentada inicialmente a história do livro "A joaninha diferente" (BRAIDO, 2008), e em seguida propusemos uma roda de conversa para discutir aspectos mais específicos da personagem, os quais contribuíram para a etapa seguinte, de reconstrução da história em grupos de aproximadamente cinco crianças. Conceitos como o de ciclo de vida foram abordados por meio de imagens impressas com o intuito de contrapor à apresentada no livro. Neste momento, além de serem evidenciados conceitos científicos, ao se comparar as diferentes representações do ciclo de vida, abordamos também os aspectos das relações de gênero apresentados na história, uma vez que esta atribui às joaninhas-fềmeas o papel de "cuidar das larvinhas" enquanto as joaninhas-machos vão para a guerra, conforme apresentado nas análises. Em seguida os grupos se uniram para reconstruir a história, colorir os desenhos das personagens e confeccionar o cenário. Ao final, cada grupo apresentou a sua história para a turma, permitindo 
que após cada apresentação os demais alunos pudessem realizar perguntas ou mesmo sugerir novas interpretações aos grupos.

Uma importante interação provocada pela peça, que inicia a sequência didática baseada na personagem joaninha, nos ajudou a ter a primeira impressão sobre a percepção das crianças referente à representação desta. Em dado momento da encenação, uma personagem se dirige ao público questionando se eles acham que a joaninha é macho ou fêmea, e a resposta foi unânime: "menina" ou "fềmea". Buscando adequar o vocabulário, a pergunta foi feita com os termos menino e menina como forma de indicar o macho e a fêmea de uma espécie. Foram realizadas outras adaptações quanto à narrativa do livro selecionado como base para a elaboração da peça, propiciando suscitar interações desta temática.

Mesmo após a personagem ter dito claramente na história que é uma joaninha-macho, percebemos a aparente dificuldade de as crianças assimilarem tal informação. Após a peça, ao serem questionados sobre esta ser menina ou menino, sob o argumento da cor da personagem, boa parte dos alunos levantaram a mão, demonstrando maior certeza quanto ao seu posicionamento por "menina". Aparentemente houve uma incerteza, mesmo apoiados na informação transmitida pela própria personagem.

Identificamos algumas possibilidades para justificar as respostas dos participantes, a) as crianças realmente não terem refletido sobre a possibilidade em existir joaninha-macho; b) não terem entendido ou escutado esse momento exato da história; c) utilização do artigo 'a' para denominar o substantivo epiceno; e, d) sua representação nos produtos culturais ocorrerem frequentemente ligadas à figura feminina: adesivos, capas de produtos, entre outros. Deste modo, os participantes só apresentaram mais convicção desta característica após a sequência de perguntas e discussão com a turma.

Para grande parte dos alunos não há problema em cores como vermelho, amarelo, laranja representar uma joaninha macho ou fêmea. Porém, ao ser mencionada uma cor que ainda é predominantemente atribuída em nossa cultura ao feminino, o rosa, a dúvida surge deixando alguns alunos pensativos. Poucos afirmaram não haver problema, incluindo um dos alunos que estava vestindo uma camiseta rosa no dia.

Esta interação entre os alunos, nos diferentes momentos da atividade, possibilitou a troca de informações e o contato com outras interpretações possíveis da obra, tendo como referencial a teoria sócio histórica de Vigotski (2007). Nessa abordagem, a estratégia didática não conduz definitivamente para o sucesso ou fracasso do processo de ensino-aprendizagem dos conceitos: ela apenas funciona como meio de ação na interação entre o parceiro mais capaz com outros. $\mathrm{O}$ parceiro mais capaz neste caso poderá ser o professor, um aluno com mais experiência, o próprio 
livro ou mesmo outro material de apoio. Apesar disso, faz-se necessário que essa estratégia proporcione a interação social, o que pode também possibilitar outros aprendizados para além do domínio cognoscitivo e ser ainda a motivação para o aprendizado.

Outra dúvida sobre a possibilidade de escolha da cor da joaninha fez com que algumas crianças apontassem que isto é definido pela cor apenas da mãe. Percebemos que o conceito científico de 'herança genética' serve como apoio implicitamente para esta afirmação. Segundo Zanon (2007), mesmo não compreendendo todos os processos envolvidos, é importante que as crianças possam refletir e estabelecer relações entre a Ciência e o seu cotidiano, uma vez que isso a fará tentar entender ou buscar compreender os porquês de coisas a sua volta. $\mathrm{O}$ fato de a figura materna ser diretamente ligada aos traços do filhote joaninha remete ao contexto cultural em que frequentemente os cuidados pelos filhos ainda são essencialmente atribuídos a ela. Isto é reforçado pelo contexto em que um suposto "pai da joaninha" nem sequer é cogitado como responsável pela cor do filhote. A menos quando perguntamos explicitamente pelo pai, e alguns afirmam depender também deste.

Esta interpretação cultural presente no conceito científico, que interliga a imagem da criança à da mãe é culturalmente simbólica e importante de ser problematizada, uma vez que essa representação acarreta efeitos sociais evidentemente desiguais para o homem e a mulher. Esta concepção pode ser reforçada também porque, em algumas espécies, é a mãe quem participa do processo de gestação dos filhos, e visualmente o pai não interfere neste processo. Os elementos das relações de gênero se fizeram presente em vários momentos, principalmente na atividade de recontar as histórias inicialmente apresentadas.

Durante a elaboração da história e da apresentação desta para os demais colegas de classe, os alunos discutiram sobre outros conceitos, os quais contemplavam diversos temas de ordem social e científica. Mesmo não tendo o dever de lidar corretamente com estes, o fato destes assuntos serem mobilizados no momento da construção da história permitiu enriquecer as observações e ampliar os argumentos utilizados para as escolhas realizadas.

Ao pensarmos nos sujeitos envolvidos nesta dinâmica, concordamos com Carvalho (2013) que, as atividades em pequenos grupos favorecem a construção da linguagem, uma vez que os estudantes se sentem mais à vontade para interagir e expressar-se. Quanto à estratégia metodológica, as atividades que envolvem as narrativas demonstram-se ainda mais produtivas para o desenvolvimento da linguagem, pois, conforme afirma Kishimoto (2010, p. 7), “as crianças gostam de ouvir histórias e também de fazer comentários. Não gostam de ficar apenas ouvindo, caladas". Logo, proporcionar este tipo de situação didática favorecerá a ampliação do 
seu repertório lúdico e linguístico, uma vez que a criança tem a oportunidade de vivenciar outras formas de ver o mundo e participar de experiências diversas (KISHIMOTO, 2010).

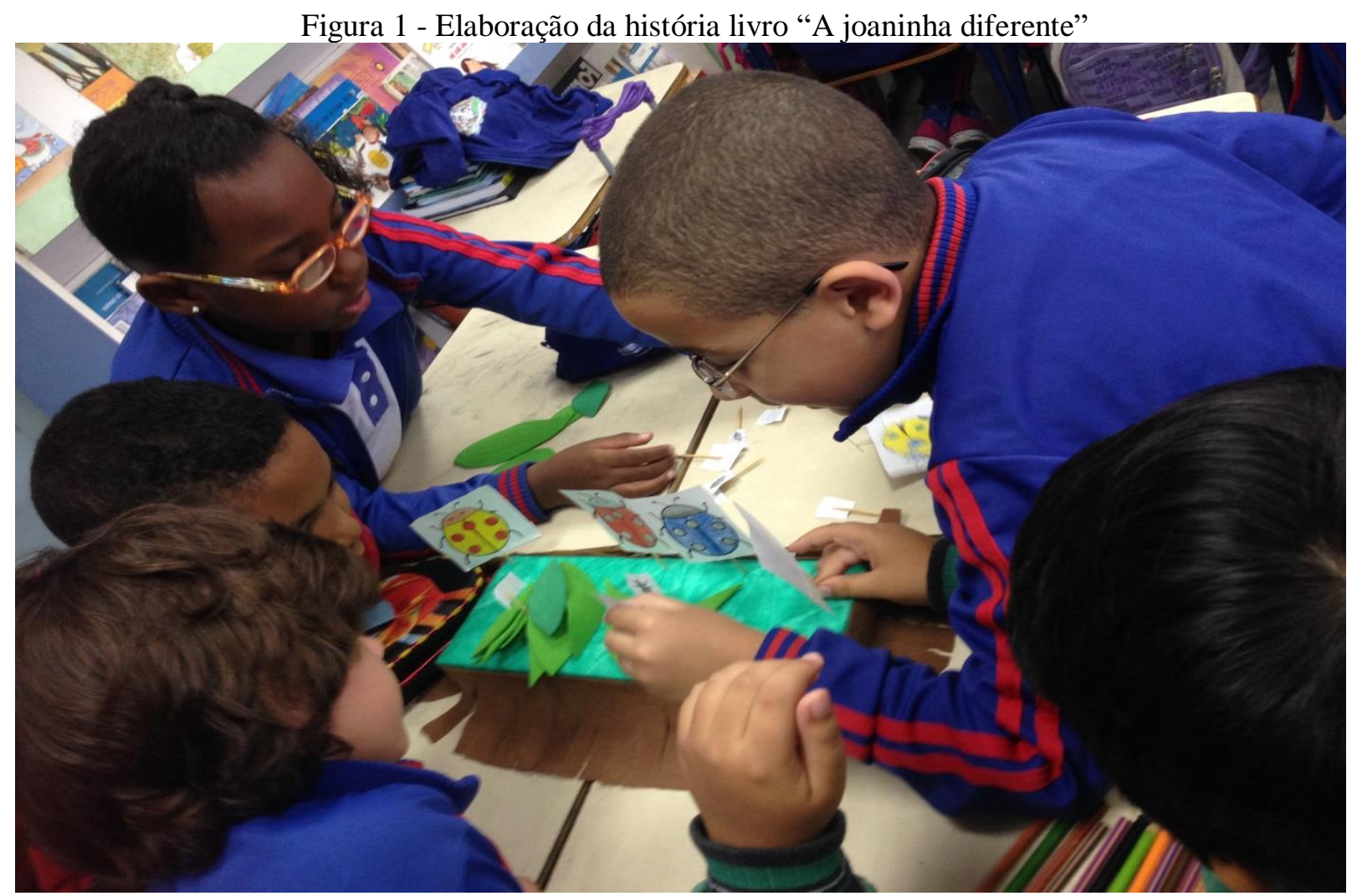

Fonte: autor, 2015.

Percebemos, a partir de alguns comportamentos apresentados pelas crianças, que, embora algumas atitudes sejam mais autorizadas socialmente às meninas/mulheres no momento da brincadeira, os objetos passam a ser ressignificados. Isto ficou ainda mais evidente no momento das apresentações, ao percebermos que em dois grupos as joaninhas-fêmeas foram à guerra, enquanto os machos ficaram para cuidar dos filhotes. Outro grupo decidiu que todas as personagens iriam para a guerra, fazendo com que não houvesse uma divisão específica para cada um dos sexos daquela espécie. De acordo com os estudos pertencentes ao campo da sociologia da infância realizados pelas pesquisadoras Finco e Oliveira, isto ocorre porque "é através das brincadeiras que a convivência com as diversas formas de ser e de se relacionar ganham potencialidade. A brincadeira possui uma qualidade social de trocas: descobrem-se significados compartilhados, recriam-se novos significados" (FARIA e FINCO, 2011, p. 73).

Embora as propostas não se constituam de situações consideradas como brincadeiras em si, dado o seu caráter direcionado pelos objetivos propostos previamente para as crianças, identificamos que o contato com os recursos empregados para apresentar as histórias criadas 
pelos alunos possam propiciar o contato maior com o plano do imaginário devido à mobilização de significados imbricados nas personagens, além de configurar um momento de interação com os demais, potencializando o processo de construção das identidades. De acordo com Kishimoto (2010), é por meio do brincar que a criança explora a natureza dos objetos, das pessoas, e da cultura, de maneira que esta passa a expressar suas individualidades e identidades, tomando decisões e conhecendo a si e ao outro.

\section{Gênero, Mídia, Educação e Pré-Adolescência}

Nem adolescentes, nem crianças, é o que diz o senso comum sobre pré-adolescentes, mas o que é, afinal, a pré-adolescência? Segundo Tomaz (2014), tanto a adolescência como a préadolescência são construções sociais recentes. Essa ideia que nós temos hoje sobre a adolescência teria se consolidado, aproximadamente, na segunda metade do século 20, inicialmente por meio de uma faixa etária que requisitava para si um estilo e um modo de vida específicos. Contudo, segundo a autora, é importante ressaltar que, atualmente, ser jovem não é algo que está imbricado com a questão temporal, é algo que vai muito além disso, ser jovem é "um ideal de vivência, de experiência e de ser" (p. 180). Já o fenômeno dos tween (ou préadolescentes), indivíduos que se encontram entre a infância e a adolescência, é ainda mais recente e, segundo Tomaz, surge "como um sintoma das alterações socioculturais das últimas décadas" (p. 178-179). Ainda nas palavras da autora (2014, p. 183),

(...) os tweens são filhos do seu tempo, criação que não teria lugar em outro momento ou sociedade, nascidos de um discurso que revela jogos de poder. As condições de visibilidade de suas práticas são históricas e não inerentes. Não se trata todavia de algo que estava oculto e foi revelado, mas de uma possibilidade que se concretizou a partir de uma configuração social, em um momento específico.

Consoante Castro (1998, p. 45), "ser 'criança' ou 'adolescente' (...) significa constituir-se a partir das condições singulares, tanto históricas como políticas e culturais que hoje se tornaram presentes e significativas no nosso cotidiano." Segundo a autora, o estabelecimento do que veio a ser chamado de cultura de consumo, por exemplo, teve grandes consequências nas formas de inserção social dos sujeitos e no âmbito das identidades. $\mathrm{O}$ advento da cultura de consumo não só expandiu e diversificou os bens e mercadorias, como também conferiu a eles o status de veiculadores de informações sobre o indivíduo que os ostenta. Além disso, segundo a autora, isso gera mudanças nas dinâmicas identitárias, a partir do momento em que, "consumir, e o que 
consumir, adquirem uma importância decisiva para definir ‘quem é quem’ no mundo social (p. 45)", especialmente entre os jovens.

Segundo Cook e Kaiser (2004), o que, atualmente, é conhecido como tween, subteen ou preteen, entendido neste trabalho como pré-adolescência, não pode ser compreendido sem que se considere sua articulação com as exigências de mercado da infância. Em seu artigo, o autor e a autora demonstram como o conceito de pré-adolescência está fortemente relacionado com uma categoria de mercado e propaganda marcada por questões de classe, raça, gênero e sexualidade. Segundo os autores, esse conceito surge ao lado da necessidade do mercado da moda de vender seus produtos para um novo público, meninas de classe média ou alta, brancas e heterossexuais, e desencadeia processos de adultização e sexualização de corpos femininos, principalmente, a partir dos anos 80 .

Consoante Tomaz (2014, p. 181), "os tweens ou pré-adolescentes são constantemente convocados a aderirem a esta experiência do que é ser jovem a partir de uma conduta comportamental prescrita a eles por meio do consumo de bens materiais e simbólicos". Ou seja, o conceito de pré-adolescência surge para designar não apenas uma fase da vida ancorando-se na idade dos indivíduos, mas também na questão do consumo, e isso tem ocorrido desde o momento em que os adolescentes explodiram, na sociedade norte-americana do pós-guerra, como um mercado consumidor extremamente lucrativo (LOURO, 2011). Nas sociedades de consumo, as identidades dos pré-adolescentes se constroem, também, a partir dos bens materiais e simbólicos que eles consomem.

Para os pré-adolescentes, adolescentes e jovens criaram-se, então, uma infinidade de produtos midiáticos. Segundo Fischer (2005), os temas e polêmicas presentes nesses produtos são quase sempre os mesmos: "amores proibidos, conflitos entre ricos e pobres, medo dos diferentes (...). É como se a ameaça do outro rondasse muitos desses produtos e fosse necessário sistemática e quase compulsivamente exorcizar, sobretudo, as diferenças de sempre (...)" (p. 22). Além disso, para a autora, esses produtos midiáticos vivem apontando as falhas dos adolescentes que estão gordos demais, que bebem muito, que engravidam muito cedo, como se tudo que ronda a adolescência fosse "demais" e fosse preciso corrigir toda essa falta de normalidade, sendo a figura feminina privilegiada por esses discursos.

Segundo Mazzarella (2009), as meninas, que por um longo período permaneceram posicionadas como um público menos do que desejável pelas mídias, a partir da década de 1990, se mostraram um público altamente lucrativo, ajudando a garantir tanto o sucesso financeiro, quanto de culto dos programas voltados para os jovens, como as séries "Buffy the Vampire Slayer" e "Dawson's Creek" vi. Segundo Catherine Driscoll (2002), as adolescentes foram 
altamente visíveis nas culturas ocidentais do século XX, a maioria como um mercado de imaturidade e identidades maleáveis. Ainda assim, muitos foram os produtos midiáticos que tiverem as meninas como seu público-alvo. Os filmes de princesas Disney, que embora não sejam voltados para as adolescentes, mas que têm as meninas como seu público-alvo, são exemplo disso. Séries televisivas com temática de contos de fada, como "Once Upon a Time", são outro exemplo de produtos midiáticos voltados para as garotas.

A atividade que vamos apresentar neste artigo, e que utiliza os produtos midiáticos citados acima, ocorreu em uma escola municipal de ensino fundamental, que está localizada na zona leste da cidade de São Paulo. A atividade ocorreu em quatro encontros com duração de aproximadamente uma hora e meia. No primeiro encontro, exibimos um trecho do filme "Branca de Neve e os Sete Anões", de 1937, da Disney. O trecho exibido mostra o primeiro encontro entre a Branca de Neve e o Príncipe Encantado. O trecho se inicia com Branca de Neve fazendo alguns serviços domésticos enquanto canta alegremente. Em seguida, após perceber a presença do Príncipe, que está cantando junto a ela, Branca corre para o castelo desesperada e se esconde, mas quando olha pela sacada e vê o Príncipe, ela fica envergonhada e se apaixona perdidamente à primeira vista.

Após a exibição, realizamos uma discussão sobre essa cena e sobre a forma como as princesas Disney, de modo geral, são representadas nos filmes, tanto nos clássicos quanto nos contemporâneos. Branca é a primeira e principal representante das princesas clássicas Disney. Tem como principal virtude sua beleza e, por essa razão, é odiada por sua madrasta malvada que pede que um caçador a mate. Durante várias cenas do filme vemos Branca exercendo trabalhos domésticos: limpando, lavando e cozinhando, sempre cantando feliz e satisfeita, além disso, ela é indefesa, ingênua e passiva, ficando apenas a espera de ser salva por seu príncipe encantado. Seu final feliz é voltar ao seu status de nobreza ficando ao lado do príncipe. No final do filme não há casamento, porém este fica implícito.

De acordo com Coca (2000, p. 13, tradução nossa),

a aparência física é mais enfatizada nas personagens femininas, assim como mais valorizada que o seu intelecto ou suas habilidades. A construção da feminilidade é feita a partir de um padrão masculino, que aprecia a obediência e a beleza. $\mathrm{O}$ primeiro longametragem Disney, Branca de Neve e os sete anões, transmite a mensagem que a beleza de uma mulher é seu recurso mais valioso, mas também fonte de inveja e descontentamento.

Os pré-adolescentes participantes dessa atividade já conheciam esse filme da Disney e

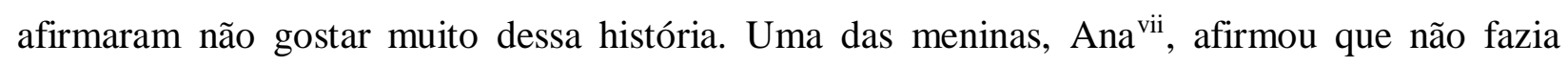
sentido a Branca de Neve correr do príncipe quando percebeu sua presença e que se ela estava 
interessada amorosamente nele, ela deveria tê-lo beijado, e não corrido. Todos também se sentiram um pouco incomodados com o fato de Branca de Neve e o Príncipe Encantado terem se apaixonado tão rapidamente (algo bem recorrente nas histórias de princesa da Disney). No geral, os participantes disseram preferir os filmes mais recentes de princesas, como "Valente" e "Frozen". Como veremos adiante, é absolutamente esperado que filmes como o da Branca de Neve, de 1937, não façam mais sucesso entre crianças e pré-adolescentes, pois esse tipo de representação feminina não convence mais as novas gerações.

No segundo encontro, também exibimos um trecho no qual a Branca de Neve e o Príncipe Encantado se encontram pela primeira vez, mas agora da série de TV "Once Upon a Time". Na cena, a carruagem do Príncipe é assaltada e ao perseguir o bandido, o Príncipe descobre que foi roubado por uma garota, a Branca de Neve. A princesa é capturada, contudo consegue escapar dando uma pedrada na cabeça do Príncipe. "Once Upon a Time” estreou, em 2011, no canal ABC (propriedade da Disney) e, no Brasil, é exibida pelo canal pago Sony e na TV aberta pela Rede Record. A série está atualmente em sua sexta temporada. Nessa série diversas personagens de contos de fada são transportadas para o "mundo real" após uma maldição ser lançada pela Rainha Má. A maior parte dos participantes já conhecia a série e mesmo os que não conheciam se mostraram interessados e afirmaram ter gostado da cena que exibimos e considerado positiva a representação da mulher nela.

Atualmente, nós podemos encontrar, na televisão, no cinema, na publicidade, etc., uma nova representação de mulheres e meninas, a mulher "empoderada". Segundo Anitta Harris (2004, p. 16-17, tradução nossa),

uma das palavras mais importantes do novo léxico do sucesso feminino jovem é "girlpower". O conceito de girlpower tem sido altamente significativo na imagem das mulheres jovens como independentes, bem sucedidas e auto inventivas. (...) Em nenhum lugar o girlpower é mais evidente do que na cultura popular, particularmente na promoção de certas popstars, heroínas de quadrinhos, personagens da televisão e do cinema e ícones da publicidade. Celebridades "girlpower" incluem temas diversos como Lara Croft, Tank Girl, Buffy a caçadora de vampiros, Courtney Love e as Spice Girls (que tinham como heroína girlpower própria, notoriamente, Margaret Thatcher). Elas são consideradas para encarnar o girlpower, porque são francas, não têm medo de tomar o poder, acreditam em si mesmas e tem controle sobre suas próprias vidas.

Não obstante, essas heroínas teen continuam seguindo determinados padrões de beleza e comportamento. São inteligentes, mas sua inteligência não é ameaçadora, lutam, mas nunca melhor do que os personagens masculinos, são independentes e não estão à espera do príncipe 
encantado, mas ter um relacionamento heterossexual e monogâmico ainda continua sendo representado como a única forma de alcançar a felicidade plena. E, normalmente, apenas mulheres cisgênero e heterossexuais têm visibilidade na mídia. Consoante Gill (2007), um dos aspectos mais importantes dos produtos midiáticos atuais é uma preocupação obsessiva com o corpo feminino. Em lugar da ideia de que o centro da feminilidade está na maternidade e no cuidado, na mídia, atualmente, a chave para a fonte da identidade e do poder feminino é ter um corpo "sexy", que precisa ser o tempo todo monitorado e disciplinado para estar sempre em conformidade com os discursos do que é ou não é atrativo.

Isso fica bem evidente nas representações femininas das princesas em "Once Upon a Time", mulheres independentes, fortes, que não estão à espera do príncipe encantado, mas que ainda mantêm características das antigas representações das princesas, principalmente no que diz respeito aos padrões de beleza. Os pré-adolescentes ainda não percebem algumas dessas sutilizas, e nós, muitas vezes, também não percebemos. Fizemos algumas discussões sobre essas questões e, em seguida, propusemos que os participantes criassem uma Branca de Neve contemporânea. No terceiro encontro, nós começamos então a criá-la. Os participantes foram imaginando como ela seria fisicamente, como se comportaria, que roupas usaria e criando uma personagem. Inicialmente, disseram que Branca teria catorze anos e usaria roupas bem curtas, mas depois começaram a repensar isso ao concluírem que é preciso primeiro criar uma personalidade para Branca, já que as roupas apenas expressariam quem ela é.

Pedimos aos participantes que, para o último encontro, pensassem mais concretamente em como seria a Branca de Neve para que tentássemos criar nossa personagem "fisicamente", utilizando cartolinas, papéis crepons, entre outros materiais. Em nossa última oficina, um dos participantes, Artur, falou ao grupo que havia escrito uma história para nossa Branca de Neve. $\mathrm{Na}$ história, Branca é uma garota muito rica que vive com a família em Nova Iorque e não recebe atenção dos pais. Sua pele é extremamente branca e seus cabelos são negros como a noite. Apesar dos esforços da família para que tenha boas maneiras, ela colocou piercings, fez tatuagens e mechas coloridas no cabelo, ninguém a compreendia. Em busca da liberdade, ela foge de casa e vai trabalhar no circo como bailarina e dançarina, onde vive para sempre feliz ao lado de seus melhores amigos, os sete anões. Ela sempre manda cartas aos pais, mas nunca diz onde está com medo de que a procurem. No circo ela podia ser quem ela é de verdade e todos gostavam dela assim, não pelos bens que ela possuía.

A história do participante é extremamente rica e interessante. Um dos pontos mais importantes a se destacar é a ausência do Príncipe Encantado. A Branca de Neve de Artur não está em busca de um homem, mas sim de liberdade, de aceitação, de autoconhecimento, ela é 
corajosa, inteligente, talentosa, e tanto sua protagonista como a sua história possuem várias características das obras e das heroínas das mídias contemporâneas. Uma das características fundamentais ao discurso midiático atual é a noção de que todas as práticas são escolhidas livremente, de que as mulheres são agentes autônomos, e que não se restringem mais pelas desigualdades de poder de qualquer natureza (GILL, 2007). Artur, provavelmente inspirado pelas mídias, colocou essas características em sua história. Sua personagem, assim como as personagens das séries, é branca e segue os padrões de beleza. Outra característica a se notar é a norte-americanização da história (título em inglês e personagem que vive em Nova Iorque). O que é esperado se considerarmos a hegemonia estadunidense.

A história do Artur convenceu os outros participantes e, assim, eles decidiram que, a Branca de Neve contemporânea seria uma artista de circo com os cabelos coloridos, piercings, várias tatuagens e usaria saia rodada e cartola. Essa escolha não foi aleatória se considerarmos que, as alunas de graduação que estavam aplicando as oficinas tinham cabelos coloridos e vários piercings e a autora deste artigo, que também estava participando das oficinas, possui várias tatuagens e piercings. Era como se, ao menos fisicamente, os participantes quisessem que a Branca de Neve fosse uma mistura das oficineiras. Assim, levamos alguns materiais e pedimos que os pré-adolescentes materializassem essa Branca de Neve que haviam criado. Infelizmente, por falta de tempo e datas para finalizarmos nossas oficinas, a Branca de Neve materializada não foi inteiramente concluída.

Figura 2 - Tatuagens da Branca de Neve

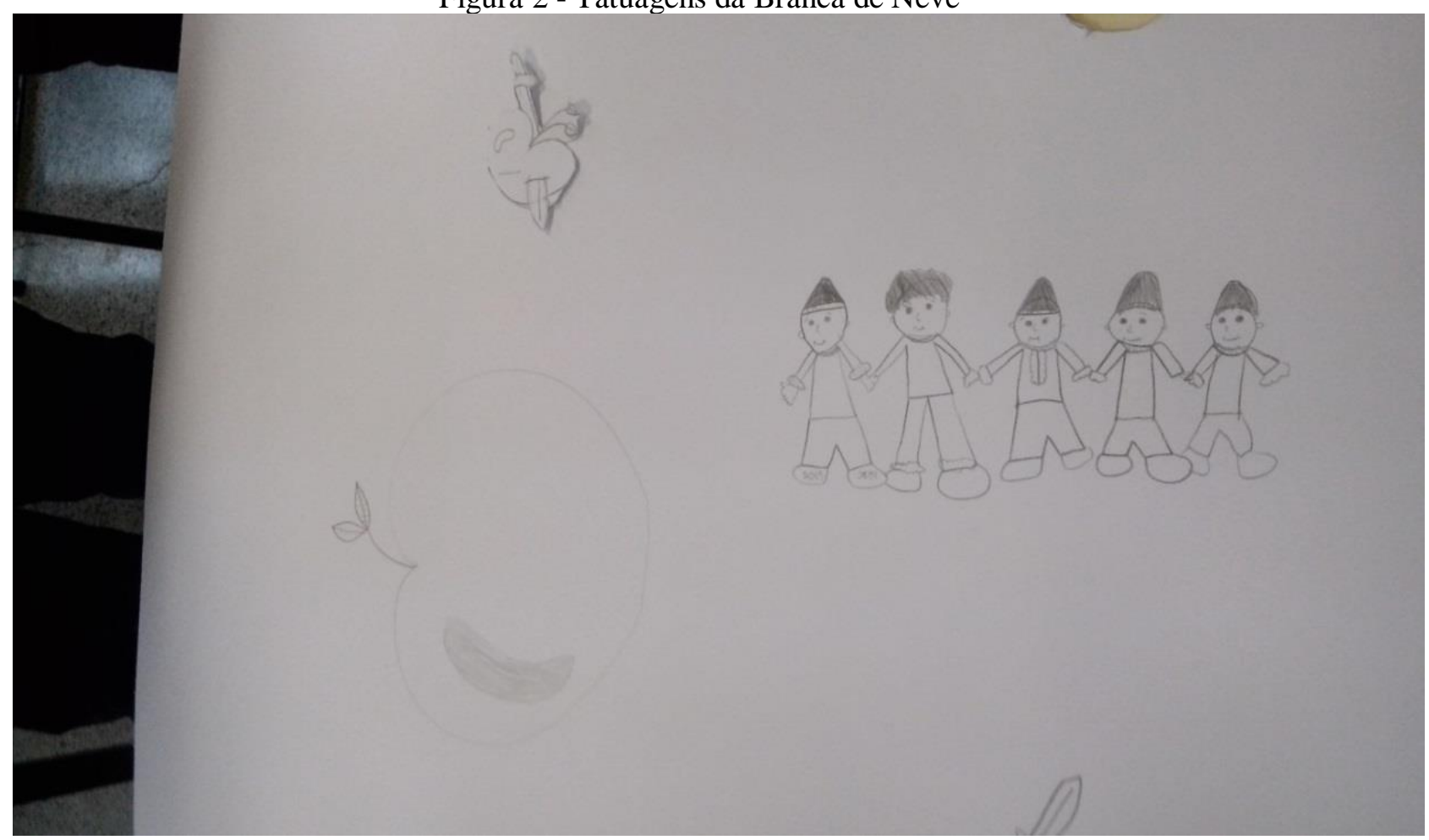

Fonte: autor, 2015 
Figura 3 - As roupas e acessórios da Branca de Neve contemporânea

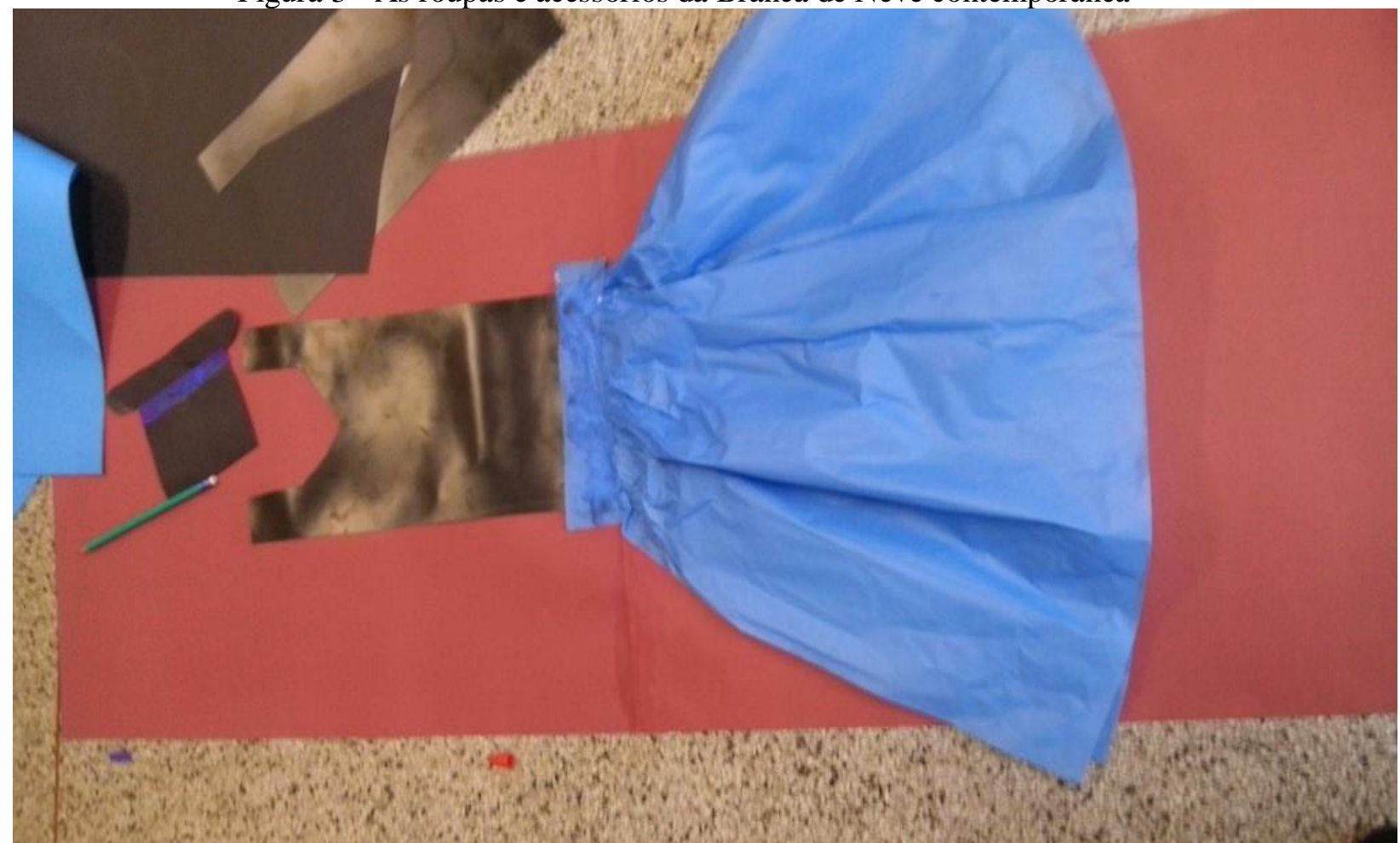

Fonte: autor, 2015.

\section{Considerações Finais}

As representações midiáticas disponíveis aos dois públicos-alvos desta pesquisa revelamse de real importância dada à sustentação simbólica que estas oferecem aos sujeitos. Embora não estabeleçamos uma relação direta entre o que estes veem e o que aprendem, desconsiderando fatores sociais e cognitivos, entendemos que a interação com determinados materiais e discursos possa influenciar a maneira como se apropriam destes, refletindo no estabelecimento de suas relações.

O planejamento das intervenções didáticas teve como princípio a construção de um espaço que promova a interação social, considerando alguns aspectos interligados. Em relação a este espaço, entendemos que, o contexto de sala de aula não se restringe ao contato entre professor e aluno, mas abarca todo o conjunto de elementos que compõem o ambiente: outros alunos, os problemas apresentados, os assuntos, as informações e valores culturais dos temas que são abordados, entre outros.

A opção de refletir sobre as falas dos alunos foi impulsionada pelo reconhecimento de dois aspectos fundamentais: a necessidade de tratá-los enquanto sujeitos que, por sua vez, estão em um processo contínuo de construção de suas identidades; e a compreensão de que os 
conteúdos abordados na escola contribuem significativamente para este momento, dado o privilégio sociopolítico que possui, principalmente ao tratarmos de um tema latente como as relações de gênero. Embora as falas dos alunos não possam ser levadas estritamente às conclusões imediatas, suas manifestações podem ser consideradas como um reflexo de aprendizados culturais resultante de diferentes interações sociais vividas.

Compreendemos que, a importância em abordar a temática aqui proposta não é mais de ordem particular, e sim pública e reconhecidamente urgente. Para tanto, o espaço escolar exerce um papel fundamental neste processo, uma vez que possui como uma de suas funções contribuir para a formação de sujeitos de direito, caracterizando-se como um rico espaço de possibilidades ao proporcionar discussões do âmbito político, cultural, histórico e social. Neste sentido, esta pesquisa visa colaborar minimamente para o processo de conscientização quanto às relações de gênero, contemplando parte de um currículo comprometido com a equidade e a valorização das diferenças, a partir da adoção de uma leitura crítica de produtos culturais voltados aos públicos infantil e pré-adolescente. Assim, temos o intuito de atingir futuros profissionais da área da educação interessados em refletir sobre a importância da ressignificação dos comportamentos sociais atribuídos às mulheres na sociedade.

\section{Referências}

ARGÜELLO, Z. E. A. Dialogando com as crianças sobre gênero através da Literatura Infantil. Dissertação (Mestrado). Programa de Pós-graduação em Educação, Universidade Federal do Rio Grande do Sul, Porto Alegre, 2005.

BRAIDO, E. A joaninha diferente. Col. Zum Zum. São Paulo, 2008.

BRANCA DE NEVE E OS SETE ANÕES (Snow White and the Seven Dwarfs). Direção: David Hand, William Cottrell, Wilfred Jackson, Larry Morey, Perce Pearce e Ben Sharpsteen. Produção: Walt Disney. Estados Unidos: Walt Disney, 1937. DVD 83 min. Son. Color.

CARVAlHO, A. M. P. (org.). Ensino de Ciências por investigação: condições para implementação em sala de aula. São Paulo: Cengage Learning, 2013.

CASTRO, L. R. (org.). Infância e Adolescência na Cultura do Consumo. Rio de Janeiro: Editora Nau, 1998.

COCA, A. A Reflection on the Development of Gender Construction in Classic Disney Films. Amsterdam Social Science, 2000. Disponível em:

<http://www.socialscience.nl/SocialScience/application/upload/files/Vol3_Is1_02Coca.pdf> Acesso em: 2014-1210.

COELHO, N. N. Literatura infantil: teoria, análise e didática. São Paulo: Moderna, 2000.

COOK, D. T.; KAISER, S. B. Betwixt and Be Tween: age ambiguity and the sexualization of the female consuming. Journal of Consumer Culture, vol. 4(2). Disponível em:

<http://joc.sagepub.com/content/4/2/203.abstract>. Acesso em 2015-03-10. 
DRISCOLL, C. Girls: feminine adolescence in popular culture and cultural theory. New York: Columbia University Press, 2002.

FARIA, A. L. G.; FINCO, D. (org.). Sociologia da Infância no Brasil. Campinas, São Paulo: Autores Associados, 2011.

FINCO, D. Educação Infantil, espaços de confronto e convívio com as diferenças: análise de interações entre professoras e meninas e meninos que transgridem as fronteiras de gênero. 2010. (Tese) Doutorado. Faculdade de Educação, Universidade de São Paulo. São Paulo, 2010.

FISCHER, R. M. B. Mídia e educação: em cena, modos de existência jovem. Revista Educar. Curitiba, ${ }^{\circ} 26, \mathrm{p}$. 17-38, 2005. Disponível em: <http://www.scielo.br/pdf/er/n26/n26a03.pdf>. Acesso em: 2015-01-30.

GAUNTLETT, D. Media, Gender and Identity: an introduction. London: Routledge, 2008.

GILL, R. Postfeminist media culture: elements of a sensibility. European Journal of Cultural Studies, 10 (2). pp. 147-166, 2007. Disponível em: <http://eprints.lse.ac.uk/2449/1/Postfeminist_media_culture_(LSERO).pdf〉. Acesso em: 2015-07-21.

GUIZZO, B. S. “Aquele negrão me chamou de leitão!”: representações e práticas corporais do embelezamento na Educação Infantil. 2011. (Tese) Doutorado. Faculdade de Educação, Universidade Federal do Rio Grande do Sul, Porto Alegre, 2011.

GUIZZO, B. S.; BECK, D. Q.; FELIPE, J. Infâncias, gênero e sexualidade: articulações possíveis. In. Infâncias, gênero e sexualidade: nas tramas da cultura e da educação. Canoas: ULBRA, 2013.

HARRIS, A. Future Girl: Young Women in the Twenty-First Century. New York: Routledge, 2004.

HARUMI, P.; MEDEIROS, V. Guia das séries: tudo que você precisa saber sobre as mais importantes dos últimos anos. São Paulo: Évora, 2014.

KELLNER, D. A cultura de mídia - estudos culturais: identidade e política entre o moderno e o pós-moderno. Bauru, SP: Edusc, 2001.

KISHIMOTO, T. M. Brinquedos e Brincadeiras na Educação Infantil. Anais do I Seminário Nacional: Currículo em Movimento: perspectivas atuais. Belo Horizonte, novembro de 2010.

LOURO, G. L. O cinema como pedagogia. In: LOPES, E. M. T.; FARIA FILHO, L. M. e VEIGA, C. G. 500 anos de educação no Brasil. Autêntica: Belo Horizonte, 2011, p. 423-446.

MAZZARELLA, S. R. Por que todos estão sempre perseguindo os jovens? O pânico moral em relação aos jovens, à mídia e à cultura. In: MAZZARELLA, Sharon R. (org.). Os Jovens e a mídia. Porto Alegre: Artmed, 2009, p 6685.

RIBEIRO, J. S. B. Brincadeiras de meninas e de meninos: socialização, sexualidade e gênero entre crianças e a construção social das diferenças. Cadernos Pagu (26), janeiro-junho de 2006: pp. 145-168.

ONCE UPON A TIME. Episódio 03: Snow Falls. In: Primeira Temporada. Criadores: Edward Kitsis e Adam Horowitz. Produção: ABC Studios. Estados Unidos: ABC Studios, 2012. DVD 947 min. Son. Color.

SCHÉRER, R. Infantis: Charles Fourier e a infância para além das crianças. Belo Horizonte: Autêntica Editora, 2009 .

SCOTT, J. W. Gênero: uma categoria útil de análise histórica. Educação \& Realidade. Porto Alegre, vol. 20, nº 2, jul./dez., 1995, pp. 71-99.

STEINBERG, S. R.; KINCHELOE, J. L. A construção corporativa da infância. Rio de Janeiro: Civilização Brasileira, 2001.

TICKLE, J.; FINN, I. A joaninha muito preguiçosa. 1ª ed. São Paulo: Ciranda Cultural, 2010. 
TOMAZ, R. A invenção dos tweens: juventude, cultura e mídia. INTERCOM - RBCC. São Paulo, v. 37, n² 2, p. 177-202, jul./dez., 2014. Disponível em: <http://www.scielo.br/pdf/interc/v37n2/1809-5844-interc-37-020177.pdf>. Acesso em: 2015-10-10.

VIGOTSKI, L.S. A formação social da mente. 7ª edição. São Paulo: Martins Fontes, 2007.

VIZACHRI, T. R. Animais-humanos ou humanos-animais? Um estudo sobre a representação dos animais antropomorfizados nos filmes de animação. Dissertação de mestrado pela EACH/USP. São Paulo, 2014.

ZANON, D. A. V. e FREITAS, D. A aula de ciências nas séries iniciais do ensino fundamental: ações que favorecem a sua aprendizagem. Ciências \& Cognição, 2007, Vol. 10: 93-103.

\footnotetext{
i Bacharela em Lazer e Turismo e Mestra em Filosofia pela Escola de Artes, Ciências e Humanidades da Universidade de São Paulo.

ii Licenciada em Ciências da Natureza e Mestra em Filosofia pela Escola de Artes, Ciências e Humanidades da Universidade de São Paulo.

iii Professor Associado da Escola de Artes, Ciências e Humanidades da USP. Bacharel e Licenciado em Física pela USP, Mestre em Ensino de Ciências pela USP, Doutor em Educação pela Faculdade de Educação da USP, LivreDocente em Artes, Cultura e Lazer pela Escola de Artes, Ciências e Humanidades da USP. Orientador do programa de pós-graduação em Educação da Faculdade de Educação USP e do programa de Estudos Culturais da EACH/USP. iv Para saber mais sobre o movimento: http://www.onumulheres.org.br/elesporelas/.

v No Brasil, "Buffy, a Caça-Vampiros“. Série exibida de 1997 a 2001 pelo canal The WB e de 2001 a 2003 pelo canal UPN. Criada por Joss Whedon, a protagonista da série, uma adolescente que descobre ser uma caçadora de vampiros, foi inspirada em importantes personagens femininas como Xena e Kitty Pryde. Whedon criou um ícone feminista ao transformar a típica patricinha norte-americana (loira, atraente e ingênua) em uma destemida heroína. Além disso, a série também revolucionou ao usar demônios e seres sobrenaturais como metáforas para os problemas enfrentados por adolescentes em fase escolar.

vi Série criada por Kevin Williamson e exibida de 1998 a 2003 pelo canal The WB, "que fez sucesso entre o público ao apresentar a juventude com charme e doçura e romantizar as descobertas e a mudança para a fase adulta" (HARUMI; MEDEIROS, 2014, p. 69).

vii Todos os nomes utilizados são fictícios, como forma de preservar a identidade dos participantes.
} 